Arq. Bras. Med. Vet. Zootec., v.70, n.6, p.1887-1898, 2018

\title{
Avaliação zootécnica e econômica da criação de camarão marinho (Litopenaeusvannamei) em diferentes estratégias de manejo e densidades
}

\author{
[Zootechnical and economical evaluation of the creation of marine shrimp (Litopenaeusvannamei) \\ in different management strategies and densities] \\ A.P. Bessa Júnior, G.G. Henry-Silva \\ Universidade Federal Rural do Semiárido - Mossoró, RN
}

RESUMO

Objetivou-se avaliar a viabilidade zootécnica e econômica na criação de camarão com três diferentes estratégias de manejo e densidades distintas, sendo 92, 14 e 8 cam.m ${ }^{-2}$ para os tratamentos M1, M2 e M3, respectivamente, com tempo máximo de cultivo de 79 dias. As sobrevivências foram reduzidas em todos os tratamentos, provavelmente influenciadas pela doença da mancha branca e a elevada salinidade da água dos viveiros de criação, o que causou redução na produção e elevou o fator de conversão alimentar aparente - FCAA em M1 e M2. Os índices de rentabilidade e lucratividade foram significativamente inferiores no tratamento M1 quando comparado com o M2 e o M3. O cultivo com população inicial elevada (M1) ocasionou prejuízos econômicos e zootécnicos devido aos elevados FCAAs, à biomassa individual reduzida e aos elevados custos operacionais totais - COT, tornando inviável esse tratamento. As taxas internas de retorno para M2 e M3 foram atrativas, gerando lucro e saldo positivo para o valor presente líquido. O monocultivo de camarão com pequenas populações e submetido à mancha branca (M2 e M3), conseguiu garantir o retorno do capital investido. Esse retorno somente ocorreu em razão dos preços elevados praticados em 2016, caso contrário, preços menores por quilo de camarão inviabilizariam economicamente a atividade.

Palavras-chave: carcinicultura, indicadores, mancha branca, sustentabilidade

\section{ABSTRACT}

The objective of this study was to evaluate the zootechnical and economic viability of shrimp farming with three different management strategies and different densities, 92, 14 and 8 shrimp. ${ }^{-2}$ for treatments M1, M2 and M3, respectively, with a maximum cultivation time of 79 days. Survival was reduced in all treatments, probably influenced by the disease of the White Spot and the high salinity of the water of the nurseries, causing reduction in the production and raising the Apparent Food Conversion Factor-FCAA in M1 and M2. The Profitability and Profitability Indices were significantly lower in the M1 treatment when compared to M2 and M3. The cultivation with high initial population (M1) caused economic and zootechnical losses due to high FCAAs, reduced individual biomass and high total operational costsTOC, making this treatment unfeasible. The internal rates of return for M2 and M3 were attractive, generating profit and a positive balance for the net present value. Monoculture of shrimp with small populations and submitted to Mancha Branca (M2 and M3), managed to guarantee the return of invested capital. This return only occurred due to the high prices practiced in 2016, otherwise, lower prices per kilo of shrimp would make the activity economically unfeasible.

Keywords: indicators, sustainability, shrimp farming, white spot

\section{INTRODUÇÃO}

Mundialmente, a aquicultura está em franca expansão devido ao fato de haver crescentes preocupações quanto à disponibilidade de alimento para a população humana, bem como de

Recebido em 14 de agosto de 2017

Aceito em 21 de novembro de 2017

E-mail: bessa@ufersa.edu.br essa atividade apresentar potencial de aumentar a resiliência do sistema alimentar global (Olsen, 2015). De acordo com dados da Comissão de Organização Mundial da Saúde (Agricultural..., 2014) entre 1980 e 2012, o volume de produção da aquicultura mundial aumentou a uma taxa média de $8,6 \%$ ao ano. Nesse contexto, nos 
últimos anos, a intensificação da aquicultura tornou-se uma prática comum em várias regiões, em razão principalmente do desenvolvimento de cultivos com elevadas populações estocadas, fertilizações intensivas, utilização de alimentação complementar e criação em sistemas multitróficos, no intuito de maximizar lucro a partir de uma unidade de área (Bessa Júnior et al., 2012; Henry-Silva et al., 2015; Montaltoet al., 2017).

Em virtude da relevância da aquicultura no que se refere ao fornecimento de alimento para a população humana, é importante que a atividade esteja sempre em busca de técnicas de manejo que melhorem a eficiência da administração dos alimentos, da qualidade da água e dos solos, com trocas mínimas de água em cultivos intensivos, visando ainda à redução da poluição e ao tratamento dos efluentes gerados, a fim de almejar sustentabilidade econômica, social e ambiental da atividade (Moura et al., 2016; Araújo e Valenti, 2017).

Entre as atividades de aquicultura, a carcinicultura se desenvolveu no semiárido do Brasil, mediante o uso águas de poços rasos com baixa salinidade e em áreas estuarinas. Essa região possui condições ambientais favoráveis para a criação de camarões, além de ter sido a pioneira em estudos técnicos que visaram à implantação e ao desenvolvimento da atividade no país (Ribeiro et al., 2014). A região Nordeste do Brasil é responsável por aproximadamente $95 \%$ da produção nacional da carcinicultura, por possuir clima quente e favorável ao cultivo durante todos os meses do ano (Rocha et al., 2004). Atualmente, a criação do camarão marinho Litopenaeusvannamei é muito difundida em regiões estuarinas do estado do Rio Grande do Norte, apesar de, em anos recentes, ter sofrido perdas significativas em consequência do vírus da síndrome da mancha branca e de doenças bacterianas (Guerrelhas e Teixeira, 2012). Em várias regiões do mundo, esforços estão sendo feitos para prevenir e controlar essa doença, que é considerada o patógeno mais temido na criação de camarão (Rubio-Castro et al., 2016).

É importante ressaltar que altas densidades populacionais de camarões e manejos alimentares com elevada quantidade de ração podem comprometer a sustentabilidade ambiental da carcinicultura, bem como deixar os organismos cultivados mais suscetíveis a doenças, além de poder ocasionar perdas econômicas com o aumento do fator de conversão alimentar e a diminuição da biomassa produzida, gerando maiores custos de produção e afetando diretamente a rentabilidade das atividades de aquicultura (Façanha, et al., 2016). Nesse contexto, o objetivo deste trabalho foi avaliar o desenvolvimento econômico e zootécnico da criação do camarão marinho $L$. vannamei em diferentes estratégias de manejo, no semiárido do estado do Rio Grande do Norte, Brasil.

\section{MATERIAL E MÉTODOS}

A pesquisa foi desenvolvida na empresa de carcinicultura conhecida como Aquarium Aquicultura do Brasil (5'11 "S, 37²0"W), localizada no município de Mossoró, no estado do Rio Grande do Norte (oeste do estado). A fazenda localiza-se próxima ao estuário hipersalino do Rio Apodi/Mossoró, onde existe uma grande quantidade de salinas. A área da carcinicultura possui 800 hectares, distribuídos em 80 viveiros de engorda, com tamanhos que variam de 0,26 a 15 ha, onde são cultivados camarão marinho L. vannamei, com densidades que variam de oito a 100 camarões.m ${ }^{-2}$. A água de abastecimento dos viveiros é parcialmente retirada do rio Apodi/Mossoró e de poços subterrâneos. De acordo com a classificação climática de Köppen, o clima da região é do tipo BSwh', isto é, semiárido muito quente e com estação chuvosa no verão atrasando-se para o outono, apresentando temperatura média de $27,4^{\circ} \mathrm{C}$, com precipitação pluviométrica anual média de $685,3 \mathrm{~mm}$ e com umidade relativa média do ar de $68,9 \%$.

O experimento foi desenvolvido com um delineamento inteiramente ao acaso, com três tratamentos. Cada tratamento foi constituído de quatro repetições, perfazendo um total de 12 unidades experimentais (viveiros), com áreas variando de 2600 a $26000 \mathrm{~m}^{2}$, sendo o tempo máximo dos experimentos de 79 dias. Anteriormenteao povoamento dos viveiros com as pós-larvas de L. vannamei, estes foram esvaziados, esterilizados, e foi mantido um vazio sanitário por 30 dias.A biomassa média individual e inicial das pós-larvas usadas foi de 0,004g (250 pls.g $\left.{ }^{-1}\right)$. Foram definidos três tratamentos com características distintas de 
manejo e população inicial estocada: manejo 1 (M1): constituído por quatro viveiros povoados com uma população inicial de 239 milheiros de pós-larvas (92 camarões. $\left.\mathrm{m}^{-2}\right)$, sistema monofásico (pós-larvas colocadas diretamente nos viveiros de engorda), fertilização inicial, que consistiu de uma mistura com $100 \mathrm{~kg} \cdot \mathrm{ha}^{-1}$ de farelo de trigo, $30 \mathrm{~kg} \cdot \mathrm{ha}^{-1}$ de nitrato de cálcio, 20kg.ha ${ }^{-1}$ de silicato e $20 \mathrm{~kg} \cdot \mathrm{ha}^{-1}$ de melaço, e fertilizações de manutenção com a aplicações quinzenais de nitrato de cálcio, na proporção de $30 \mathrm{~kg} \cdot \mathrm{ha}^{-1}$, e semanal de melaço, na proporção de

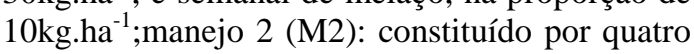
viveiros povoados com uma população inicial de 364 milheiros de pós-larvas (14 camarões.m ${ }^{-2}$ ), sistema monofásico e fertilização inicial semelhante ao M1, porém sem fertilizações de manutenção, ou seja, sem a aplicação quinzenal de nitrato de cálcio e semanal de melaço;manejo 3 (M3): composto por duas fases distintas:afase 1 foi constituída por um berçário secundário estocado com 1.000 camarões. $\mathrm{m}^{-2}$, tipo raceway, coberto com lona com dimensões de 20x100m, onde as pós-larvas foram estocadas por um período de 30 dias. A fertilização inicial foi à base de uma mistura com $250 \mathrm{~kg}_{\text {. ha }}{ }^{-1}$ de farelo de trigo, $45 \mathrm{~kg} \cdot \mathrm{ha}^{-1}$ de nitrato de cálcio e $40 \mathrm{~kg} \cdot \mathrm{ha}^{-1}$ de melaço, sendo adicionado, ainda, $0,2 \mathrm{~kg} \cdot \mathrm{ha}^{-1} \mathrm{de}$ probiótico (cultura única ou mista de microrganismos vivos), constituído de Bacillusspp. e Lactobacillussp., previamente ativado em caixas de 1.000 litros por $24 \mathrm{~h}$ com melaço e água do próprio viveiro. Semanalmente, foi inoculado $0,1 \mathrm{~kg} \cdot \mathrm{ha}^{-1} \mathrm{de}$ probiótico e $20 \mathrm{~kg} \cdot \mathrm{ha}^{-1}$ de melaço (quantidades sugeridas por Avnimelech(2009), para manter uma relação $\mathrm{C} / \mathrm{N}$ acima de 10 ). Na segunda fase, os juvenis de L. vannamei, com biomassa média individual de $0,98 \pm 0,05 \mathrm{~g}$, foram despescados e estocados em quatro viveiros de engorda, cada um com uma população inicial de 208 milheiros de pós-larvas estocados (oito camarões.m $\mathrm{m}^{-2}$ ). Cada um dos viveiros foi fertilizado inicialmente com $30 \mathrm{~kg} \cdot \mathrm{ha}^{-1}$ de nitrato de cálcio e $100 \mathrm{~kg} \cdot \mathrm{ha}^{-1}$ de calcário dolomítico. Fertilizações semanais foram realizadas utilizando-se $10 \mathrm{~kg} \cdot \mathrm{ha}^{-1}$ de nitrato de cálcio até a despesca.

O arraçoamento para os três tratamentos consistiu na oferta de ração por meio do método de voleio. Três tipos de rações comerciais com diferentes composições foram utilizados durante o experimento. Fase 1: ração usada desde o povoamento até 10 dias de cultivo (40\% $\mathrm{PB}$ ); fase
2: ração usada logo após a fase 1 até o camarão atingir 3g (40\% PB);fase 3 (ração de engorda), utilizada a partir de $3 \mathrm{~g}$ até a despesca (35\% PB). Durante o experimento, os camarões foram alimentados inicialmente quatro vezes ao dia, com oferta de ração a $10 \%$ da biomassa até os indivíduos atingirem cerca de $1 \mathrm{~g}$. A partir desse momento, a taxa de alimentação foi gradativamente reduzida até $2 \%$ da biomassa no final do experimento, sendo ofertado o alimento em duas refeições diárias. As variáveis físicoquímicas transparência, salinidade, temperatura, $\mathrm{pH}$ e oxigênio dissolvido (OD) foram mensuradas quinzenalmente, totalizando, ao longo do cultivo, quatro coletas. Foi utilizado um disco de Secchi e um multissensor de parâmetro de qualidade da água (HORIBA U-50). Todas as coletas foram realizadas próximo às comportas de drenagem dos viveiros,nos períodos diurno e noturno, sendo às sete horas e às 18h, respectivamente. Visando identificar a presença ou a ausência do vírus da mancha branca (white spot syndrome vírus - WSSV) nos tratamentos, foi realizada análise molecular das amostras dos pleópodos dos camarões cultivados ( $L$. vannamei). $\mathrm{O}$ método utilizado foi análise quantitativa por qPCR em tempo real, utilizandose o sistema de detecção TaqMan PCR (Life technologies $($ ) e a plataforma ABI 7500 (AppliedBiosystem ${ }^{\circledR)}$ para a detecção e a quantificação dos vírus da síndrome da mancha branca (WSSV). Foram coletadas e analisadas amostras de todos os tratamentos. As análises foram realizadas no Centro de Diagnóstico de Enfermidades de Organismos Aquáticos Cedecam, do Instituto de Ciências do Mar Labomar da Universidade Federal do Ceará.

Semanalmente foram capturados, com tarrafas com malhas de 8 a $10 \mathrm{~mm}$, aproximadamente $10 \%$ dos animais dos viveiros, com o intuito de se realizarem as biometrias e de se quantificarem os parâmetros zootécnicos. O ganho de massa foi calculado pela diferença entre a biomassa atual e a biomassa da pesagem anterior, enquanto o ganho de massa médio final foi calculado dividindo-se a biomassa total final pelo número de indivíduos que sobreviveram. A sobrevivência, medida em percentual, foi calculada com base na quantidade de animais despescados dividido pelo número de indivíduos estocados multiplicado por 100. A produção foi obtida por meio da soma de biomassa, em quilos, de todos os animais despescados e extrapolada 
para a área de 1ha. O fator de conversão alimentar aparente (FCAA) foi calculado de acordo com a ração total ofertada dividido pela soma das biomassas finais dos camarões. As análises de custos foram do tipo ex-post, ou seja, custos calculados ao final do ciclo produtivo. Os dados dos preços pagos pelos insumos e víveres foram obtidos junto às instituições privadas, produtoras específicas de cada produto. Os dados dos preços praticados na comercialização em função da gramatura final dos animais foram obtidos por meio de entrevista informal junto à empresa Aquarium, que comercializa suas produções com preços praticados nos estados do Rio Grande do Norte e Ceará. A modalidade de custo analisada neste trabalho corresponde aos gastos totais por hectare/ano de área cultivada (custo total operacional - CTO), abrangendo os custos fixos e os custos variáveis.

Foram considerados como medidas de resultado econômico os seguintes itens: receita bruta (RB), que corresponde ao valor da produção obtida por hectare; lucro operacional (LO), que corresponde à diferença entre a receita bruta $(\mathrm{RB})$ e custos totais operacionais (CTO); índice de rentabilidade (IR), que é a receita bruta (RB) dividida pelos custos totais operacionais (CTO) e o índice de lucratividade (IL), calculado dividindo-se o LO pela RB. Foi calculada ainda a relação renda investimento (RRI), que é igual à renda anual dividido pelo investimento inicial:

$$
T I R=\sum_{i=0}^{n} \frac{B_{i}-C_{i}}{(1+T I R)^{i}}=0
$$

Taxa interna de retorno (TIR),

sendo:

$\mathrm{B}_{\mathrm{i}}=$ benefício total no ano $\mathrm{i}$ (receitas);

$\mathrm{C}_{\mathrm{i}}=$ custo total no ano $\mathrm{i}$ (capital + despesas operacionais);

$\mathrm{n}=$ horizonte do empreendimento.

$\mathrm{i}=0,1,2, \ldots . . . ., \mathrm{n}$.

$$
P R C=\sum_{i=0}^{j} F L C_{i}=0
$$

Período de retorno do capital (PRC) ou payback; sendo:

$\mathrm{j}=$ PRC, em anos;
$\mathrm{FLC}_{\mathrm{i}}=$ fluxo líquido anual do empreendimento no ano $\mathrm{i}$;

$\mathrm{n}=$ horizonte do empreendimento

$\mathrm{i}=0,1,2, \ldots \mathrm{j} \ldots, \mathrm{n}$.

$$
R B C=\frac{\sum_{i=0}^{n} \frac{Y_{i}}{(1+r)^{i}}}{\sum_{i=0}^{n} \frac{K_{i}}{(1+r)^{i}}}
$$

Relação benefício/custo (RBC);

sendo:

$\mathrm{Y}_{\mathrm{i}}=$ benefício líquido anual no ano $\mathrm{i}$ (receita bruta menos as despesas operacionais);

$\mathrm{K}_{\mathrm{i}}=$ capital investido no ano $\mathrm{i}$ (investimento inicial mais reinvestimentos);

$\mathrm{r}=$ taxa de desconto do empreendimento (taxa de atratividade);

$\mathrm{n}=$ horizonte do empreendimento.

$\mathrm{i}=0,1,2, \ldots \mathrm{j} \ldots, \mathrm{n}$.

$$
V P L=\sum_{i=0}^{n} \frac{B_{i}-C_{i}}{(1+r)^{i}}
$$

Valor presente líquido(VPL);

sendo:

$\mathrm{B}_{\mathrm{i}}=$ benefício total no ano $\mathrm{i}$, (receitas);

$\mathrm{C}_{\mathrm{i}}=$ custo total no ano $\mathrm{i}$ (capital + despesas operacionais);

$\mathrm{r}=$ taxa de desconto do empreendimento (taxa de atratividade);

$\mathrm{n}=$ horizonte do empreendimento;

$\mathrm{i}=0,1,2, \ldots \ldots, \mathrm{n}$.

Foram mensurados ainda a diversidade do produto (DP), o número de produtos oferecidos pelo empreendimento e a diversidade de mercado (DM), bem como o número de mercados que absorvem a produção.

Para testar a normalidade e a homocedasticidade dos resultados relacionados às variáveis limnológicas, zootécnicas e econômicas, foram utilizados os testes de D'Agostinho e de Bartlett, respectivamente. Para as variáveis que apresentaram distribuição normal e variância homogênea, foi aplicada análise de variância (ANOVA one-way) e, a posteriori, o teste de Tukey, que identificou diferenças significativas $(\mathrm{P}<0,05)$ entre os tratamentos. 


\section{RESULTADOS E DISCUSSÃO}

A temperatura da água esteve dentro dos limites considerados adequados para a criação de camarões (Valenti, 1985), ou seja, com valores médios variando de 28,5 a $29,0^{\circ} \mathrm{C}$ (Tab. 1). Entretanto, é importante destacar que, de acordo com Trejo-Flores et al., (2016), intervalos de temperatura entre 28 e $30^{\circ} \mathrm{C}$ tendem a favorecer infecção do camarão pela mancha branca. Os valores médios de ODficaram entre 5,6 e 7,2mg. $\mathrm{L}^{-1}$, próximos aos encontrados porKrishna, et al. (2015), que trabalhou com densidades iniciais de estocagem variando de 40 a 80 cam.m $\mathrm{m}^{-2}$, obtendo valores médios de OD

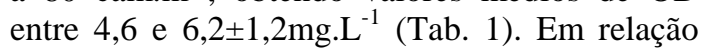
aos valores médios de salinidade, pôde-se constatar que eles foram elevados em todos os tratamentos (41,8 em M1; 46,0 em M2 e 61,1 em M3) (Tab. 1). A salinidade ideal para cultivo do L. vannamei é de 15 e $25 \mathrm{~g} . \mathrm{L}^{-1}$, e o ponto de equilíbrio osmótico para essa espécie é de 24,7g.L L $^{-1}$ (Boyd, 1989). Esses valores elevados de salinidade provavelmente se devem à localização dos viveiros de carcinicultura, que ficam próximos à região estuarina do rio Apodi/Mossoró e que, por sua vez, recebem efluentes de salinas.

Tabela 1. Valores médios e desvios-padrão das variáveis limnológicas da água de cultivo do L. vannamei com diferentes tratamentos. Letras distintas indicam diferenças significativas pelo teste de Tukey $(\mathrm{P}<0,05)$

\begin{tabular}{lccc} 
& \multicolumn{3}{c}{ Tratamentos } \\
\hline \multicolumn{1}{c}{ Variáveis limnológicas } & $\mathrm{M} 1$ & $\mathrm{M} 2$ & $\mathrm{M} 3$ \\
\hline Transparência $(\mathrm{cm})$ & $31,2 \pm 8,6^{\mathrm{a}}$ & $33,7 \pm 3,1^{\mathrm{a}}$ & $33,2 \pm 1,1^{\mathrm{a}}$ \\
Salinidade $\left(\mathrm{g} . \mathrm{L}^{-1}\right)$ & $41,8 \pm 1,4^{\mathrm{a}}$ & $46,0 \pm 1,6^{\mathrm{a}}$ & $61,1 \pm 0,9^{\mathrm{b}}$ \\
Temperatura $\left({ }^{\circ} \mathrm{C}\right)$ & $28,9 \pm 0,2^{\mathrm{a}}$ & $29,0 \pm 0,6^{\mathrm{a}}$ & $28,5 \pm 0,1^{\mathrm{a}}$ \\
$\mathrm{pH}$ & $8,4 \pm 0,1^{\mathrm{a}}$ & $8,4 \pm 0,1^{\mathrm{a}}$ & $7,8 \pm 0,2^{\mathrm{a}}$ \\
Oxigênio dissolvido $\left(\mathrm{mg} . \mathrm{L}^{-1}\right)$ & $7,2 \pm 0,7^{\mathrm{a}}$ & $5,6 \pm 1,2^{\mathrm{a}}$ & $7,0 \pm 0,8^{\mathrm{a}}$ \\
\hline
\end{tabular}

Os resultados das análises das amostras de camarões dos três tratamentos $\mathrm{M} 1, \mathrm{M} 2$ revelaram a presença do vírus da síndrome da mancha branca em $100 \%$ das amostras (Tab. 2). Guertleret al. (2013) registraram uma carga viral elevada de de $5,6 \times 10^{6}$, que resultou em $100 \%$ de mortalidade da população de camarão nos primeiros cinco dias de cultivo. A temperatura da água dos viveiros pode ter auxiliado na manifestação da doença, pois vários autores citam que, em temperaturas variando entre $22 \mathrm{e}$ $30^{\circ} \mathrm{C}$, foram registradas mortalidades massivas atribuídas ao WSSV (Centro de Investigaciones Biológicas del Nordeste, 2008; Costa et al., 2010; Rubio-Castro et al., 2016; Trejo-Flores et al., 2016).

Tabela 2. Carga viral de WSSV obtida por meio da análise molecular das amostras dos pleópodos dos camarões cultivados (L. vannamei) analisadas pelo método quantitativo por qPCR em tempo real

\begin{tabular}{|c|c|c|}
\hline & \multicolumn{2}{|c|}{ WSSV } \\
\hline & DNA viral & $\begin{array}{c}\text { Carga viral } \\
\text { (cópias/ } \mu \mathrm{g} \text { de DNA) }\end{array}$ \\
\hline M1 - amostra 01 & Detectado & $1,39 \times 10^{2}$ \\
\hline M2 - amostra 01 & Detectado & $8,43 \times 10^{1}$ \\
\hline M3 - amostra 01 & Detectado & $4,59 \times 10^{1}$ \\
\hline & Percentual de detecção & $100 \%$ \\
\hline
\end{tabular}

Os valores médios de sobrevivência para os tratamentos M1, M2 e M3 foram de 42,9\%, $12,2 \%$ e $39,3 \%$, respectivamente (Fig. 1). Não foram constatadas diferenças significativas entre os tratamentos M2 e M3. Já em M1, a sobrevivência foi significativamente superior às sobrevivências observadas em M2 e M3. A salinidade elevada, provavelmente em razão do período de estiagem na região e da grande concentração de salinas próximas ao local de criação, pode ter sido uma das causas da baixa sobrevivência dos camarões em todos os tratamentos. Decampet al. (2003) obtiveram sobrevivência de 94\%, ao cultivarem $L$. vannamei com salinidade de $36 \mathrm{~g} . \mathrm{L}^{-1}$, e Maia et al. (2016) identificaram sobrevivência de $84 \%$, 
quando trabalharam com densidade de 98 cam.m 2 em salinidade de $22 \mathrm{~g} . \mathrm{L}^{-1}$, ou seja, salinidades menores daquelas registradas neste trabalho. Os resultados de Azevedo et al. (2013) corroboram que, em salinidades mais baixas, a sobrevivência dos camarões tende a ser mais elevada, pois, em pesquisa com 300 cam.m $\mathrm{m}^{-2}$ cultivados em salinidade inferior a $5 \mathrm{~g} . \mathrm{L}^{-1}$, os autores obtiveram sobrevivência média acima de $83 \%$. Outro fator que pode ter contribuído para a elevada mortalidade foi a constatação do vírus da mancha branca em 100\% das amostras analisadas. TrejoFlores et al. (2016) obtiveram sobrevivências semelhantes $(50 \%)$ às encontradas neste trabalho, uma vez identificada a contaminação de $L$. vannamei por esse patógeno.

Diferenças significativas do FCAA foram encontradas entre todos os tratamentos, sendo o valor em M1 (2,95/1) significativamente superior aos valores observados nos tratamentos M2 (1,44/1) e M3 (0,22/1) (Fig.1). A sobrevivência média de apenas $42,9 \%$, associada ao excesso de ração ministrada durante todo o cultivo em M1, pode ter contribuído para valores mais elevados de FCAA. Já a sobrevivência reduzida de 12,2\% em M2 provavelmente foi o principal fator que contribui para um FCAA significativamente superior em comparação aos demais tratamentos. Um dos motivos que podem ter proporcionado um FCAA significativamente inferior em M3 pode estar relacionado à estratégia de manejo adotada, que favoreceu o crescimento compensatório dos camarões causado pelas diferenças de densidades ao se transferirem os indivíduos de um ambiente de cultivo para outro, ou seja, passando da fase 1 (berçário), com 1.000 cam. $\mathrm{m}^{-2}$, para a fase 2 (viveiro de engorda), com 8 cam. $\mathrm{m}^{-2}$.Sookying e Davis (2011) e Brito et al. (2016), que trabalharam com diferentes estratégias de manejo alimentar no cultivo do $L$. vannamei com elevadas populações iniciais estocadas, obtiveram FCAA de 1,31 e sobrevivência de 94\%, superior às encontradas neste trabalho, corroborando que quanto mais elevada a sobrevivência, maior será a biomassa total, reduzindo, consequentemente, o FCAA.
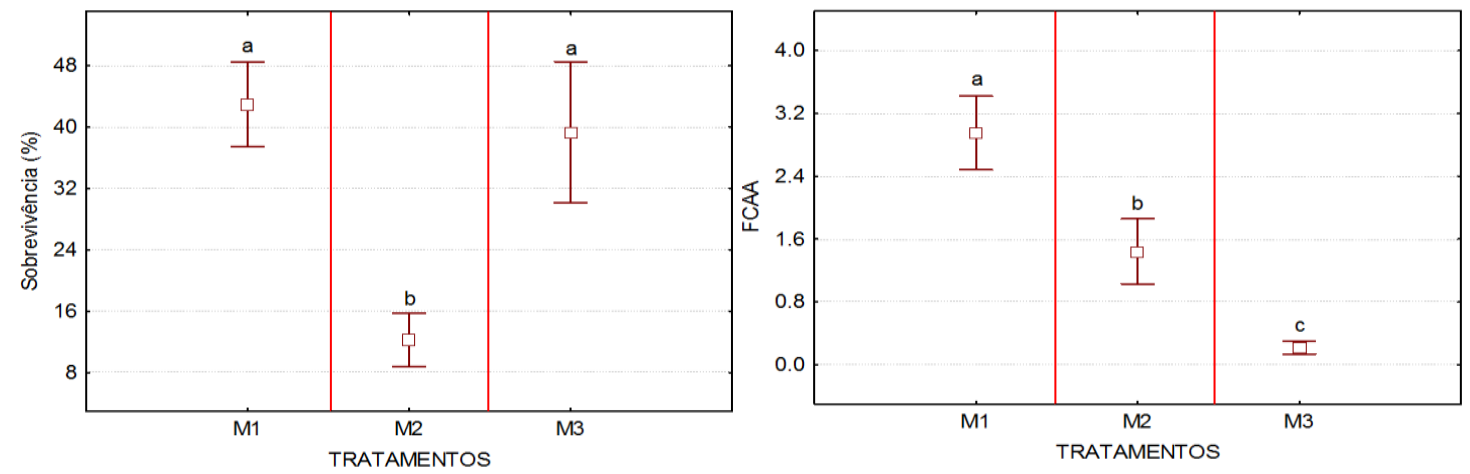

Figura 1. Valores médios e desvios-padrão do fator de conversão alimentar aparente - FCAA e da sobrevivência média dos camarões L. vannameinos diferentes tratamentos. Letras distintas indicam diferenças significativas pelo teste de Tukey $(\mathrm{P}<0,05)$.

Os tratamentos M1, M2 e M3 apresentaram biomassa individual final média de $6,3 \mathrm{~g}$ (65 dias de cultivo) 9,4g (79 dias de cultivo) e $6,9 \mathrm{~g}$ (51 dias de cultivo), respectivamente (Fig. 2). Não foram constatadas diferenças significativas entre as biomassas individuais finais de L. vannamei entre os tratamentos M1 e M3 (Fig. 2). A biomassa individual final de L. vannamei em M2 foi significativamente superior em relação aos demais tratamentos, provavelmente em decorrência da sobrevivência baixa, pois quanto menor a população de camarão, menor a competição por espaço e/ou por alimento, que tende a favorecer uma biomassa individual final mais elevada dos indivíduos. De fato, Bessa Júnior et al. (2012) e Simão et al. (2013) também constataram que quanto menor a população final dos camarões, maior será a biomassa individual final dos indivíduos.

Ao final dos cultivos, os valores médios de biomassa total foram de $651,9 \mathrm{~kg} \cdot \mathrm{ha}^{-1}$ em M1, $332,2 \mathrm{~kg} \cdot$ ha $^{-1}$ em M2 e 219,0kg.ha ${ }^{-1}$ em M3. Não foram verificadas diferenças significativas entre as biomassas totais dos camarões em M2 e M3, no entanto a biomassa total em M1 foi 
significativamente superior em relação aos demais tratamentos (Fig. 2). Os valores significativamente superiores de biomassa total de L. vannamei em M1 provavelmente decorreram da densidade de estocagem inicial mais elevada (98 cam. $\mathrm{m}^{2}$ ), se comparadas às densidades de estocagem nos tratamentos M2 (14 cam. $\left.\mathrm{m}^{2}\right)$ e M3 $\left(8 \mathrm{cam} \cdot \mathrm{m}^{2}\right)$. No entanto, apesar de a densidade de estocagem inicial em M1 ter sido sete vezes maior que em M2 e aproximadamente 13 vezes maior que em M3, os valores finais de biomassa total em M1 foram apenas cerca de duas e três vezes maiores que os valores constatados em M2 e M3, respectivamente. Maia et al. (2016) estocaram camarões com densidade semelhante a M1 (98 cam.m $\left.{ }^{-2}\right)$ e obtiveram biomassa final média de $8.875 \mathrm{~kg} \cdot \mathrm{ha}^{-1}$, com sobrevivência média de $84 \%$, sendo os camarões despescados com uma biomassa individual final de $11,3 \mathrm{~g}$. Isso corrobora que quanto maior a sobrevivência e a biomassa individual dos animais despescados, maior será a biomassa total produzida.
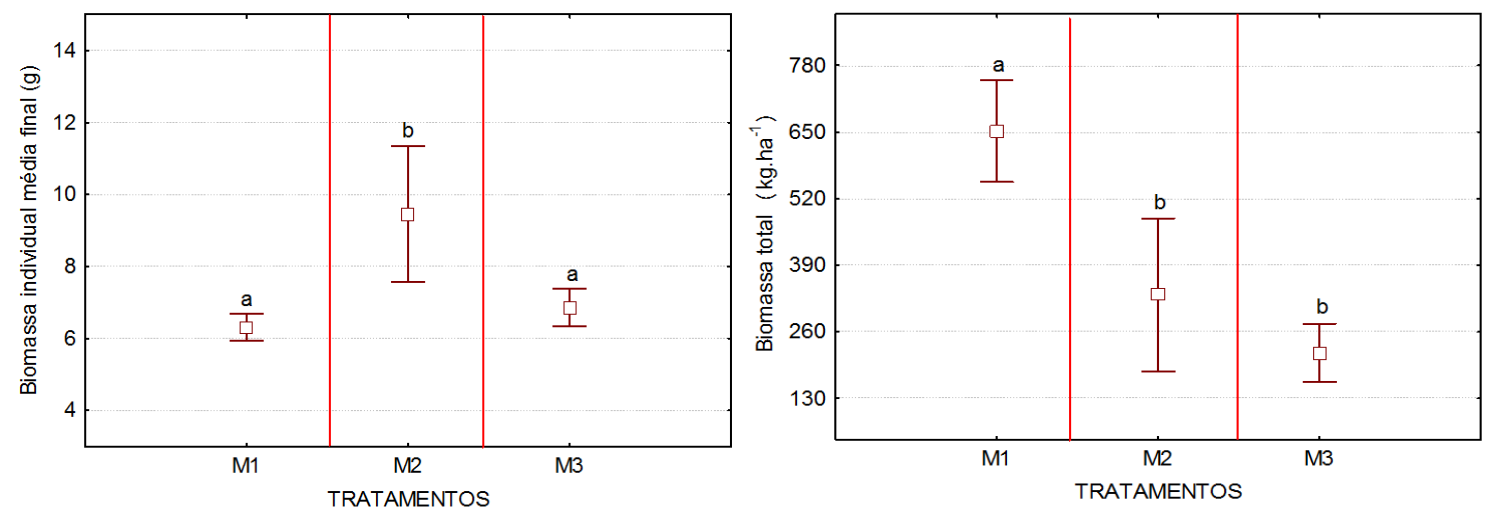

Figura 2. Valores médios e desvios-padrão da biomassa individual média e total dos camarões $L$. vannameinos diferentes períodos e tratamentos durante o cultivo. Letras distintas indicam diferenças significativas pelo teste de Tukey $(\mathrm{P}<0,05)$.

As análises econômicas foram baseadas em dados obtidos com a produção e os preços praticados no comércio. Os valores médios, pagos por kg de camarão aos produtores durante a comercialização do produto final, são referentes ao ano de 2016 (Tab. 3). Os preços médios praticados nos estados do Rio Grande do Norte e Ceará foram elevados em razão da baixa oferta do camarão causada pela reduzida produtividade das carciniculturas localizadas em ambos os estados, no ano de 2016, provavelmente pelo surto da mancha branca. Os valores médios pagos foram de $\mathrm{R} \$ 24,20$ para os camarões dos tratamentos M1 e M3, e de R\$ 27,88 para os camarões do tratamento M2 (Tab. 3). A diferença de preço do $\mathrm{kg}$ de camarão para os diferentes tratamentos está relacionada à biomassa individual média final.

Tabela 3. Preços médios de comercialização dos camarões praticados no mercado do Rio Grande do Norte e do Ceará, no ano de 2016

\begin{tabular}{cccccc}
\hline $\begin{array}{c}\text { Classificações } \\
(\mathrm{g})\end{array}$ & $<8,30$ & $8,31-10$ & $10,1-12,4$ & $12,5-14$ & $14,1-16$ \\
\hline Preço $(\mathrm{R} \$)$ & 24,48 & 27,88 & 30,92 & 32,62 & 35,20 \\
\hline
\end{tabular}

Fonte: Pesquisa com produtores locais.

A receita bruta $-\mathrm{RB}$ registrada no tratamento M1 foi significativamente superior a M2 e M3, registrando uma receita de $\mathrm{R} \$ 74.299,50$ (Fig. 3). Não foram verificadas diferenças significativas das RB para M2 (R $\$ 42.892,50)$ e M3 (R\$ 40.013,13). Para os custos totais operacionais -
CTO, todos os tratamentos apresentaram diferenças significativas, sendo M1 (R\$ 205.968,55) significativamente superior a M2 (R\$ 25.526,83) e M3 $(30.638,93)$. Em M2, os CTOs foram significativamente inferiores a M3 (Fig. 3). Os valores de RB e CTO elevados em 
M1, provavelmente, foram em razão da população inicial, do tempo de cultivo e do elevado FCAA, pois custos com rações e póslarvas podem comprometer em até $60 \%$ os custos de produção (Bessa Júnior et al., 2012; Sanches et al., 2013). Em qualquer sistema de produção, a comercialização deve se dar de forma que as receitas superem o capital investido. Nesse contexto, custos operacionais elevados inviabilizam o rendimento líquido máximo dos sistemas de cultivo, necessitando um aumento nos preços de venda e/ou redução nos custos de produção (Valderrama e Engle, 2002; Costa, 2005; Sanches et al., 2014; Bezerra, 2017).

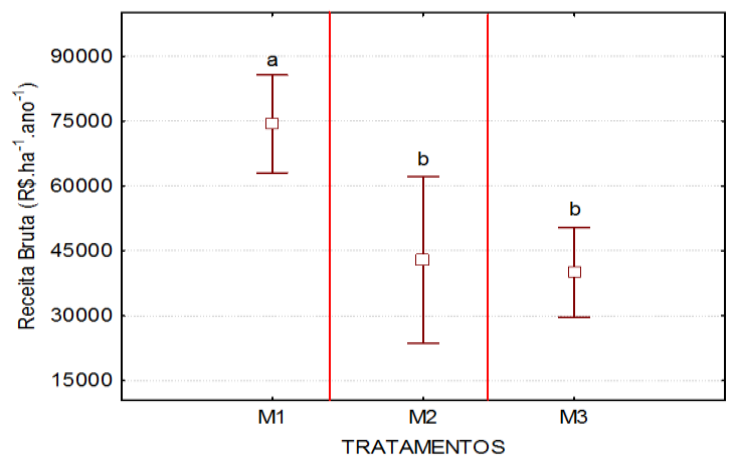

Shang e Merola (1987) ressalvam que o aumento da biomassa individual, atrelada à sobrevivência, constitui estratégia para minimizar o custo de produção por unidade de peso, aumentando o retorno do capital investido. Em M3, os elevados valores de CTO podem ter sido em razão da estratégia de manejo, que utilizou estufa (raceway) para produzir uma pós-larva maior $(1,0 \mathrm{~g})$, tornando os custos com ela $\left(\mathrm{R} \$ 36,00 . \mathrm{mil}^{-}\right.$ $\left.{ }^{1}\right)$ superiores a M2 $\left(\mathrm{R} \$ 8,50 \cdot \mathrm{mil}^{-1}\right)$. É importante destacar que pesquisas adicionais na produção de camarão em raceway são necessárias para melhorar a tecnologia superintensiva e reduzir custos com a produção (Samochaet al., 2011).

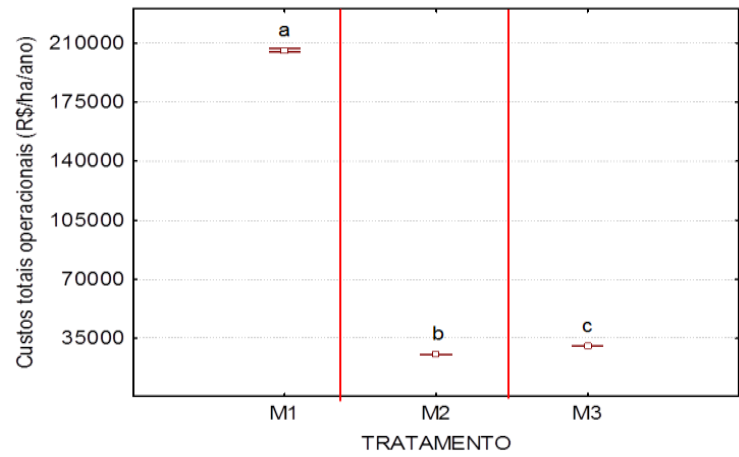

Figura 3. Valores médios e desvios-padrão da receita bruta - RB e dos custos totais operacionais - CTO no cultivo do L. vannamei nos diferentes tratamentos. Letras distintas indicam diferenças significativas pelo teste de Tukey $(\mathrm{P}<0,05)$.

Os custos por kg de camarão produzido em M1, M2 e M3 foram de R\$ 58,74, R\$ 17,85 e R\$ 19,14, respectivamente (Tab. 4), em razão do elevado custo em M1. O preço pago por $\mathrm{kg}$ de camarão desse tratamento não cobre os custos operacionais, inviabilizando economicamente a atividade. Já os tratamentos M2 e M3, devido ao menor custo operacional, podem gerar lucros que variam de $\mathrm{R} \$ 17.365,67$ e $\mathrm{R} \$ 9.374,20 . \mathrm{ha}^{-1}$.ano1 , respectivamente. O menor lucro. $\mathrm{kg}^{-1}$ em M3 foi provocado pelos custos com o manejo no raceway.

Tabela 4. Valores médios de produção por ha/ano, lucro e custos $\mathrm{R} \$ / \mathrm{kg}$ na produção do camarão marinho $L$ vannameiem diferentes tratamentos, para se gerar lucro ou prejuízo em função da produção

\begin{tabular}{cccc} 
& Produção média & Lucro & Custo \\
\hline Tratamentos & $(\mathrm{kg} / \mathrm{ha} / \mathrm{ano})$ & $(\mathrm{R} \$ / \mathrm{kg})$ & $(\mathrm{R} \$ / \mathrm{kg})$ \\
\hline M1 & $3.506,64$ & 37,46 & 58,74 \\
M2 & $1.429,75$ & 12,15 & 17,85 \\
M3 & $1.600,53$ & 5,86 & 19,14 \\
\hline
\end{tabular}

Não se verificou diferença significativa da taxa interna de retorno - TIR, para os tratamentos M2 (33,7\% aa) e M3 (28,8\% aa), ou seja, valores mais elevados que a taxa básica de juros - Selic $(13,6 \%$ aa), o que demonstra a viabilidade econômica dessa atividade quando praticada com cultivos menos adensados. Em M1, não se verificou a TIR pelo fato de os lucros se apresentarem negativos (Tab. 5). Os valores médios da TIR encontrados em M2 e M3 foram mais elevados que os encontrados por Bezerra (2017), identificando-se TIR de 21,48\% para um 
cenário de investimentos sem financiamento e próximo aos encontrados por Sanches et al. (2014) no cultivo do robalo-flecha, os quais identificaram TIR de $28 \%$.

O valor presente líquido - VPL em M1 foi negativo,pois o valor presente de pagamentos futuros, descontados a uma taxa de juros de 8,5\% ao ano, não se pagou e acumulou prejuízos. Sanches et al. (2013) citam que, se a subtração dovalor atual dos benefícios do valor atual dos custos ou desembolsos for positiva, o investimento é considerado financeiramente viável. Dessa forma, apenas os tratamentos M2 e M3 foram considerados viáveis economicamente, sendo o VPL menor em M3 (Tab. 5), devido ao investimento em estufa, que teve como intuito produzir camarões com biomassa individual maior e provavelmente mais resistentes ao vírus da mancha branca. Os fatores que mais afetam para mais ou para menos o VPL são os custos com investimentos, formas jovens e rações (Sanches et al., 2014). Em M3, o lucro foi inferior a M2 em aproximadamente 46\% (Tab. $5)$, isso em razão do custo de produção da póslarva e da biomassa individual média final. Nos três tratamentos, a diversidade de produto foi baixa $(1,0)$ devido ao sistema de cultivo (monocultivo). Já a diversidade de mercado $(6,0)$ foi considerada alta, pois a produção foi comercializada em vários estados, principalmente São Paulo, Santa Catarina, Pernambuco, Ceará, Rio Grande do Norte e no Distrito Federal (Tab. 5).

O período de retorno do capital - PRC, em anos para o tratamento $\mathrm{M} 1$, foi negativo em virtude do valor presente líquido - VPL, o qual se mostrou impagável para um fluxo de caixa com projeção para 20 anos, pois, considerando-se os investimentos e os custos operacionais, a dívida acumulada pode chegar a $\mathrm{R} \$ 2.697 .770,52$. O PRC em M3 (6,34 anos) foi menor que M2 (8,61 anos) provavelmente em consequência do tempo de cultivo, o que possibilitou um maior número de ciclos por ano (Tab. 5). É importante destacar que algumas atividades de aquicultura garantem o retorno do capital em menos de quatros anos. Bezerra (2017) constatou PRC menor que o encontrado em M3, ou seja, 4,38 anos. Já Sanches et al. (2014) observaram que o PRC no cultivo do robalo-flecha foi de três anos, ou seja, retorno do investimento bem mais rápido do que o constatado no presente trabalho. Os PRC elevados em M2 e M3 podem estar associados à reduzida biomassa final produzida, refletindo na RB menor; dessa forma, o tempo para o retorno do capital se torna maior.

Tabela 5. Valores obtidos para indicadores de sustentabilidade econômica do cultivo de L. vannamei nos diferentes tratamentos

\begin{tabular}{lrrr}
\hline \multicolumn{1}{c}{ Indicadores } & \multicolumn{1}{c}{ M1 } & M2 & \multicolumn{1}{c}{ M3 } \\
\hline Receita bruta (R\$) & $74.299,50$ & $42.892,50$ & $40.013,13$ \\
Custo operacional total(R\$) & $205.968,54$ & $25.526,83$ & $30.638,93$ \\
Relação renda investimento (R\$) & $-1,38$ & 0,53 & 0,44 \\
Taxa interna de retorno (\%) & - & 33,70 & 28,89 \\
Período de retorno do capital (anos) & $-0,82$ & 8,61 & 6,34 \\
Relação benefício custo (R\$) & $-12,80$ & 3,41 & 2,23 \\
Valor presente líquido (R\$) & $-1.283 .297,85$ & $121.084,48$ & $38.270,21$ \\
Lucro (R\$) & $-131.364,94$ & $17.375,33$ & $9.374,20$ \\
Índice de rentabilidade & 0,36 & 1,68 & 1,31 \\
Índice de lucratividade & $-1,81$ & 0,33 & 0,32 \\
Diversidade de produtos & 1,00 & 1,00 & 1,00 \\
Diversidade de mercado & 6,00 & 6,00 & 6,00 \\
\hline
\end{tabular}

Os índices de rentabilidade (IR) e a lucratividade (IL) foram significativamente inferiores no tratamento M1 quando comparado com M2 e M3
(Fig. 4), provavelmente em razão dos elevados CTO impulsionados pelos valores médios significativamente superiores de FCAA. Não se 
verificaram diferenças significativas para esses índices entre os tratamentos M2 e M3. Os IR foram de 1,68 e 1,31 para M2 e M3, respectivamente, demonstrando a viabilidade da atividade, uma vez que esses índices apontam quanto se pode gerar em RB para cada um real (R\$ 1,00) investido em CTO. Os índices de lucratividade (IL) foram positivos para os tratamentos M2 $(0,33)$ e M3 $(0,32)$, pois, para cada $\mathrm{R} \$ 1,00$ gerado na forma de receita, foram verificados lucros de $R \$ 0,33$ e $R \$ 0,32$, respectivamente. IL mais elevado foi identificado por Bezerra (2017), registrando valor de 1,52. No entanto, este valor foi menor do que o encontrado por Campos e Campos (2006), que identificaram IL de 9,4, ou seja, índice muito superior ao encontrado no presente trabalho, demonstrando que elevadas populações iniciais podem inviabilizar economicamente a carcinicultura, especialmente na presença do vírus da mancha branca.
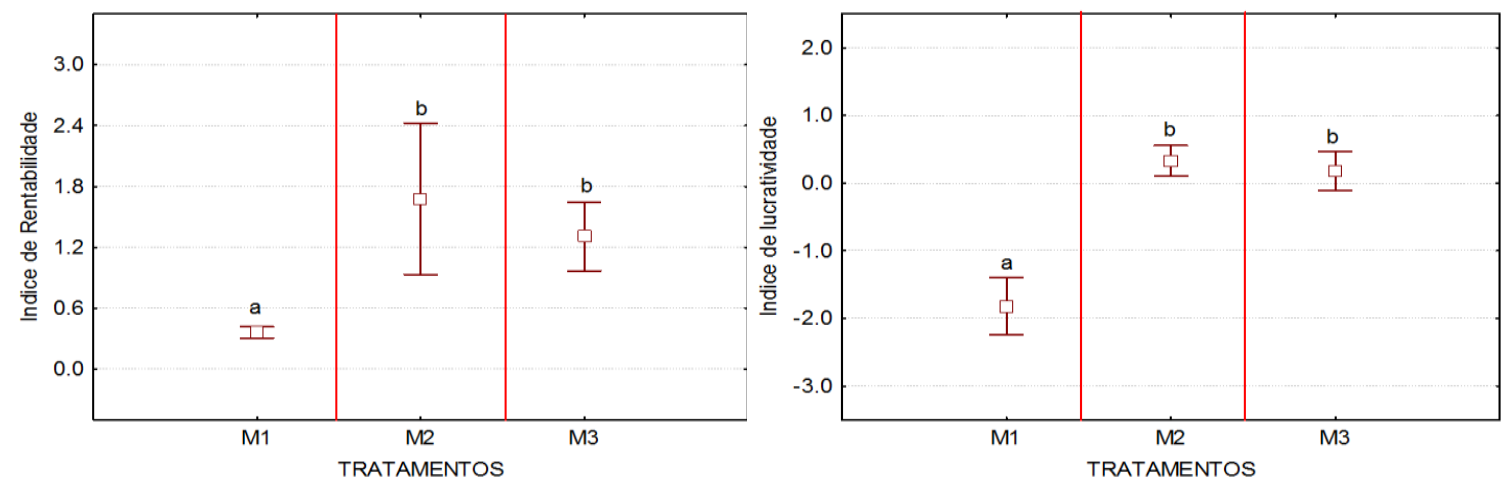

Figura 4. Valores médios mais desvio-padrão dos índices de rentabilidade (IR) e de lucratividade (IL) gerados no cultivo do L. vannamei nos diferentes tratamentos. Letras distintas indicam diferenças significativas pelo teste de Tukey $(\mathrm{P}<0,05)$.

\section{CONCLUSÃO}

A atividade de carcinicultura marinha no semiárido nordestino passa por um período crítico em consequência da invasão de patógenos, tais como o vírus da mancha branca, bem como do longo período de estiagem a que a região está sendo submetida nos últimos cinco anos. Produtores vêm buscando alternativas para tornar a atividade viável economicamente, por meio do emprego de diferentes estratégias de manejo e da redução das populações de camarões estocadas, com o intuito de inibir manifestações de doenças mediante diminuição do tempo de cultivo, o que gera mais ciclos e receitas por ano. Nesse contexto, constatou-se, no presente trabalho, que os cultivos adensados com elevadas populações iniciais, como no tratamento M1, geram prejuízos econômicos e zootécnicos em razão da sobrevivência reduzida, dos elevados FCAAs e da baixa biomassa individual e total produzida, configurando-se em uma atividade insustentável. A pesquisa demonstrou que o monocultivo de camarão, quando realizado com pequenas populações de camarões e submetido ao vírus da mancha branca, como constatado nos tratamentos M2 e M3, ainda consegue garantir o retorno do capital investido em um período de seis a oito anos. Deve-se salientar que esse retorno do capital ocorreu devido aos preços praticados no mercado no ano de 2016; caso contrário, preços menores pagos por quilo de camarão também tornariam esses cultivos inviáveis economicamente. Conclui-se que, no atual cenário da atividade de carcinicultura, cultivos praticados com a utilização de menores populações iniciais com o intuito de se produzirem animais com biomassas individuais médias finais maiores, tendem a gerar mais lucros devido ao menor tempo de cultivo, ao maior número de ciclos por ano e aos preços mais elevados pagos a camarões maiores.

\section{AGRADECIMENTOS}

Os autores agradecem à empresa Aquarium Aquicultura do Brasil, por disponibilizar suas estruturas, técnicos e encarregados responsáveis pelo cultivo de camarão, para a realização desta pesquisa. 


\section{REFERÊNCIAS}

AGRICULTURAL Outlook. Paris: FAO / OECD Publishing, 2014.

ARAÚJO, M.C.; VALENTI, W.C. Effects of feeding strategy on larval development of the Amazon River prawn Macrobrachiumamazonicum.Rev. Bras. Zootec., v.46, p.85-90, 2017.

AVNIMELECH, Y. Biofloc technology: a practical guide book. Baton Rouge: World Aquaculture Society, 2009. [p.19-21].

AZEVEDO, C. M. S. B.; SALES, R. B. S.; ARRUDA, A. M. V.; SIMÃO, B. R.; BRITO, L. O. 2013. Desempenho do camarão Litopenaeusvannamei em sistema sem renovação de água com diferentes níveis de proteína bruta e adição de melaço. Arquivos de Ciências do Mar. v.46, p.40-46, 2013.

BESSA JUNIOR, A.P.; AZEVEDO, C.M.S.B.; PONTES, F.S.T.; HENRY-SILVA, G.G. PolycultureofNiletilapiaandshrimpatdifferentstoc kingdensities. Rev. Bras. Zootec., v.41, p.15611569, 2012.

BEZERRA, M.A. Indicadores de sustentabilidade na aquicultura brasileira: um estudo de caso na carcinicultura marinha no estado do Ceará. 2017. 167f. Tese (Doutorado em Ciências Marinhas Tropicais) - Instituto de Ciências do Mar da Universidade Federal do Ceará, Fortaleza, CE.

BOYD, C. E. Water quality management and aeration in shrimp farming.2nd ed. Alabama Fisheries and Allied Aquacultures Departmental.Agricultural Experiment Station. Auburn University, Alabama, USA. 1989.

BRITO, L. O.; CHAGAS, A. M.; SILVA, E. P; SOARES, R. B.; SEVERI, W.; GALVEZ, A.O. Water quality, Vibrio density and growth of Pacific white shrimp Litopenaeusvannamei (Boone) in an integrated biofloc system with red seaweed Gracilariabirdiae (Greville). AquacultureResearch. v.47, p.940-950, 2016.

CAMPOS, K.C.; CAMPOS, R.T. Alternativa econômica para o novo rural do Nordeste brasileiro: o cultivo do camarão Litopenaeusvannameiem água doce. Rev. GEPEC, vol.10, p.40-53, 2006.
COSTA, J.E.L. A carcinicultura na região de Mossoró. 2005. 56f. Monografia (Especialização em Carcinicultura) - Universidade Federal Rural do Semi-Árido, Mossoró/RN.

COSTA, S.W.; VICENTE, L.R.M.; SOUZA, T.M.; ANDREATTA, E.R. et al. Parâmetros de cultivo e a enfermidade da manchabranca em fazendas de camarões de Santa Catarina. Pesqui. Agropecu. Bras., v.45, p.1521-1530, 2010.

DECAMP, O.; CODY, J.; CONQUEST, L.; DELANOY, G. et al. Effect of salinity on natural community and production of $L$. vannamei(Boone), within experimental zerowater exchange culture systems. Aquaculture Res., v.34, p.345-355, 2003.

FAÇANHA, F.N.; OLIVEIRA-NETO, A.R.; FIGUEIREDO-SILVA， C.; NUNES, A.J.P. Effect of shrimp stocking density and graded levels of dietary methionine over the growth performance of Litopenaeusvannamei reared in a green-water system. Aquaculture, v.463, p.16-21, 2016.

GUERRELHAS, A.C.B.; TEIXEIRA, A.P. Panorama da situação da Mancha Branca no Nordeste. Panorama Aquicult., v.22, p.38-41, 2012.

GUERTLER, C.; RIEG, T.; MEJIA-RUIZ, C.H.; LEHMANN, M. et al. Hemograma e sobrevivência de camarões marinhos após silenciamento do WSSV por RNA de interferência. Pesqui. Agropecu. Bras., v.48, p.983-990, 2013.

HENRY-SILVA， G.G.; MAIA， C.S.P.; MOURA, R.S.T.; BESSA JUNIOR, A. P. et al. Integrated multi-trophic culture of Nile tilapia (Oreochromisniloticus) and Amazon river prawn (Macrobrachiumamazonicum) in brackish water. Arq.Bras. Med. Vet. Zootec., v.67, p.265-273, 2015.

KRISHNA, P.V.; PRAKASH, B.K.; KUMAR, V.H.; PRABHAVATHI, K. Growth, survival and production of pacific white shrimp Litopenaeusvannameiat different stocking densities under semi intensive culture systems in andhrapradesh. Int. J. Adv. Res., v.3, p.446-452, 2015. 
MAIA, E.P.; MODESTO, G.A.; BRITO, L.O.; GALVEZ, A.O. et al. Intensive culture system of Litopenaeusvannameiin commercial ponds with zero water exchangeand addition of molasses and probiotics. Rev. Bio. Mar. Ocean., v.51, p.61-67, 2016.

MONTALTO, V.; MARTINEZ, M.; RINALDI, A.; SARÀ, G. et al.The effect of the quality of diet on the functional response of Mytilusgalloprovincialis (Lamarck, 1819): Implications for integrated multitrophic aquaculture (IMTA) and marine spatial planning. Aquaculture, v.468, p.371-377, 2017.

MOURA, R.S.T.; VALENTI, W.C.; HENRYSILVA, G.G. Sustainability of Nile tilapia netcage culture in a reservoir in a semi-arid region.Ecol. Indicators, v.66, p.574-582, 2016.

OLSEN, Y. How can mariculture better help feed humanity? Front. Mar. Sci. v.2, p. 46 (2015)

RESUMEN ejecutivodel informe final delproyectoprograma integral de sanidadacuícolaencamarón. La Paz: CIBNOR, 2008. p.33.

RIBEIRO, L.F.; SOUZA, M.M.; BARROS, F.; HARTJE, V. Desafios da carcinicultura: aspectos legais, impactos ambientais e alternativas mitigadoras. Rev. Gestão Costeira Integr., v.14, p.365-383, 2014.

ROCHA, I.P.; RODRIGUES, J.; AMORIN, L. A carcinicultura brasileira em 2003. Rev. ABCC, v.6, p.30-36, 2004.

RUBIO-CASTRO, A.; LUNA-GONZÁLEZ, A.; ÁLVAREZ-RUÍZ, P.; ESCAMILLA-MONTES, R.et al. Survival and immune-related gene expression in Litopenaeusvannamei co-infected with WSSV and Vibrio parahaemolyticus. Aquaculture, v.464, p.692-698, 2016.

SAMOCHA, T.M.; MORRIS, T.C.; KIM, J.S.; CORREIA, E.S. et al. Avanços recentes na operação de racewayssuperintensivos dominados por bioflocos e com renovação zero para a produção do camarão branco do Pacífico, Litopenaeusvannamei. Rev. ABCC, v.13, p.6267, 2011.
SANCHES, E.G.; SILVA, F.C.; RAMOS, A.P.F.A. Viabilidade econômica do cultivo do robalo-flecha em empreendimentos de carcinicultura no Nordeste do Brasil.Bol. Inst. Pesca, v.40, p.577-588, 2014.

SANCHES, E.G.; TOSTA, G.A.M.; SOUZAFILHO, J.J. Viabilidade econômica da produção de formas jovens de bijupirá (Rachycentroncanadum). Bol. Inst. Pesca, v.39, p.15-23, 2013.

SHANG, Y.C.; MEROLA, N. Manual de economia de la aquicultura. Brazilia: FAO, 1987. (Programa Cooperativo Gubernamental. Proyecto GCP/RLA/075/ITA. Apoyo a lasactividadesregionales de acuacultura para America Latina y el Caribe).

SIMÃO, B. R.; BRITO, L. O.; MAIA, A. S. C.; MIRANDA, L. C. et al. Comparing stocking densities and feeding strategies in a shrimp and tilapia polyculture in tanks. PesquisaAgropecuáriaBrasileira, v.48, n.8, p.1088-1095, 2013.

SOOKYING, D.; DAVIS, D.A. Pond production of Pacific white shrimp (Litopenaeusvannamei) fed high levels of soybean meal in various combinations. Aquaculture, v.319, p.141-149, 2011.

TREJO-FLORES， J. V.;LUNA-GONZÁLEZ, A.; ÁLVAREZ-RUÍZ, P.; ESCAMILLAMONTES, R. et al. Protective effect of Aloe vera in Litopenaeusvannamei challenged with Vibrio parahaemolyticus and white spot syndrome vírus. Aquaculture, v.465, p.60-64, 2016.

VALDERRAMA.D.; ENGLE, C.R. Economic optimization of shrimp farming in Honduras.J. World Aquacult. Soc., v.33, p.398-404, 2002.

VALENTI. W.C. Cultivo de camarões de água doce. São Paulo: Nobel, 1985. 82p. 